\title{
Îles et continents
}

Karolina Resztak and Hervé Sanson

URL: https://journals.openedition.org/coma/865

DOI: $10.4000 /$ coma.865

ISSN: 2275-1742

Publisher

Institut des textes \& manuscrits modernes (ITEM)

\section{Electronic reference}

Karolina Resztak and Hervé Sanson, "Îles et continents", Continents manuscrits [Online], 8 | 2017, Online since 15 March 2017, connection on 13 January 2023. URL: http://journals.openedition.org/coma/865 ; DOI: https://doi.org/10.4000/coma.865

This text was automatically generated on 13 January 2023.

\section{c) (i) (9)}

Creative Commons - Attribution-NonCommercial-NoDerivatives 4.0 International - CC BY-NC-ND 4.0 https://creativecommons.org/licenses/by-nc-nd/4.0/ 


\title{
Îles et continents
}

\author{
Karolina Resztak and Hervé Sanson
}

1 Ce numéro huit de la revue Continents manuscrits, à l'enseigne des "Iles et continents ", se veut un numéro de varias, une fois n'est pas coutume. Iles et continents car: du Congo aux Antilles, en passant par l'Amérique du Nord, le numéro assume sa géographie plurielle, polycentrée. Le panorama d'auteurs représentés dans la revue est riche et varié : de Joseph Zobel à Sony Labou Tansi, d'Aimé Césaire à Nathanaël, ou René Maran, c'est bien des cartographies mises en relation que ce numéro témoigne.

2 La revue Continents Manuscrits a le plaisir tout d'abord d'inviter dans ses colonnes la revue Caribbean Quarterly en rééditant trois de ses articles réunis dans un numéro intitulé Caribbean Literary Archives (volume 62, 2016 ; numéros 3-4, Francis \& Taylor Online). Alison Donnell, Rachel Douglas et Alex Gil proposent dans leurs contributions une réflexion précise, détaillée, sur les fonds d'archives caribéens, et notamment celui d'Aimé Césaire. Cette reprise d'articles précédemment publiés par nos confrères de Caribbean Quarterly, outre qu'elle témoigne de centres d'intérêts communs, et d'un souci partagé quant à la sauvegarde et la valorisation de ces fonds d'archives, permet de promouvoir ces travaux auprès d'un autre lectorat.

3 Kora Véron pour sa part se propose de retracer la genèse mouvementée d'un recueil tel que Les Armes miraculeuses à partir de la prise en compte du site André Breton et des archives Césaire qui s'y trouvent. Céline Gahungu et Ninon Chavoz se penchent quant à elles sur le «cas" Sony: la première interroge la genèse d'un ensemble complexe, mouvant, transgénérique ayant pour titre $\mathrm{L} a$ Gueule de rechange, et montre combien l'entreprise sonyenne défie, dès les commencements, toute catégorisation; la seconde, à partir d'un compte-rendu critique des Poèmes de Sony Labou Tansi publiés chez CNRS éditions en 2015, dépasse l'exercice proprement dit pour livrer une réflexion sur la poétique de l'écrivain congolais.

4 La rubrique «Entretien» propose une exploration de l'œuvre de l'auteur avantgardiste Nathanaël. Vivant en Amérique du Nord, écrivant en français et en anglais, se livrant par ailleurs à une activité de traducteur, ses textes assument une déconstruction des catégories génériques, tant littéraires que sexuelles. C'est à un véritable questionnement des processus de genèse de la création mais aussi de la 
méthode de travail de l'écrivain, ainsi que de son rapport aux archives, que nous invite cet entretien.

5 La rubrique "Témoignage » livre, depuis les lettres échangées par l'écrivain avec sa femme demeurée en Martinique, et avec un ami proche, lettres à ce jour inédites, l'analyse du sentiment d'exil singulier qui saisit Joseph Zobel, le célèbre auteur de La rue Case-Nègres, lorsqu'il arrive en métropole, et les premiers pas de l'auteur cherchant à obtenir reconnaissance puis consécration auprès de ses pairs.

6 Enfin, la rubrique "Inédit" propose l'introduction de Charles Scheel aux documents retrouvés dans la réserve de la bibliothèque universitaire de l'UCAD par Nicolas MartinGranel et Philip Janzen. Le dossier présenté par Charles Scheel contient, entre autres, la correspondance entre le jeune écrivain martiniquais Joseph Zobel et René Maran qui bénéficiait à cette époque d'une notoriété certaine. Les lettres échangées entre les deux écrivains, les conseils que Joseph Zobel reçoit de son aîné ainsi que les œuvres dédicacées qu'il envoie à Maran, restent encore à découvrir. Notre connaissance de cette archive sera approfondie par un nouveau groupe de travail "Zobel", récemment constitué dans le cadre de notre équipe.

7 Nous avons eu la douleur d'apprendre le décès de notre collègue Anne BegenatNeuschäfer, survenu le 3 mars dernier, des suites d'une longue maladie. Qu'il nous soit permis de rendre un hommage appuyé à notre collègue et amie, qui a toujours soutenu nos différents projets avec un enthousiasme inentamé, et alors même qu'elle était déjà très malade. Son optimisme inébranlable, son énergie, son volontarisme, ne l'ont jamais abandonnée, y compris dernièrement, dans sa lutte contre le mal qui la rongeait. Nous garderons le souvenir d'une véritable chercheuse, dotée d'une curiosité contagieuse, mais également, et c'était là une de ses dimensions qui nous l'attachait immédiatement, d'une grande humanité et d'un contact chaleureux avec ses interlocuteurs. Anne faisait partie du comité scientifique de la revue, et y avait publié un article "Ahmadou Kourouma, un fonds en cours de classement » dans le numéro 5.

Le parcours académique et scientifique d'Anne Begenat-Neuschäfer fut riche et diversifié. Elle avait soutenu une thèse d'état en 1983 sur le Théâtre du Soleil (De l'improvisation au rite. La "Comédie de notre temps » au Théâtre du Soleil, publiée chez Peter Lang en 2002) puis travaillé sur la Renaissance française (Agrippa d'Aubigné, Marguerite de Navarre) et italienne (Lodovico Dolce, Matteo Bandello), avant de s'intéresser à la littérature belge d'expression française (Bauchau, Mertens). Elle avait traduit Henry Bauchau en allemand (Edipe sur la route, Diotime et les lions, ainsi qu'une sélection de poèmes). Elle travaillait ces dernières années sur les littératures africaines, aussi bien d'expression française (Ahmadou Kourouma) que d'expression portugaise (Paulina Chiziane). Depuis 1998, Anne était titulaire d'une chaire à l'Institut de philologie romane de l'Université d'Aachen (RWTH). Elle dirigeait également le Centre de Langue et de Littérature françaises de Belgique.

Nous n'aurons de cesse de perpétuer au sein de notre revue l'esprit d'ouverture et la curiosité intellectuelle qui caractérisaient Anne Begenat-Neuschäfer. Qu'elle repose en paix. L'équipe « Manuscrits francophones » présente ses très sincères condoléances aux proches d'Anne. 


\section{AUTHORS}

\section{KAROLINA RESZTAK}

Chercheuse associée à l'ITEM

\section{HERVÉ SANSON}

Chercheur associé à l'ITEM 